\title{
A binderless, covalently bulk modified electrochemical sensor: Application to simultaneous determination of lead and cadmium at trace level
}

\author{
Raghu Gunigollahalli Kempegowda, Pandurangappa Malingappa* \\ Department of Studies in Chemistry, Bangalore University, Central College Campus, Bangalore 560001, India
}

\section{A R T I C L E I N F O}

\section{Article history:}

Received 13 January 2012

Received in revised form 24 February 2012

Accepted 28 March 2012

Available online 11 April 2012

\section{Keywords:}

Graphitic carbon

4-Aminosalicylic acid

Binderless bulk modified electrode

Lead

Cadmium

Battery waste water

\begin{abstract}
A B S T R A C T
A new type of covalent binderless bulk modified electrode has been fabricated and used in the simultaneous determination of lead and cadmium ions at nanomolar level. The modification of graphitic carbon with 4-amino salicylic acid was carried out under microwave irradiation through the amide bond formation. The electrochemical behavior of the fabricated electrode has been carried out to decipher the interacting ability of the functional moieties present on the modifier molecules toward the simultaneous determination of $\mathrm{Pb}^{2+}$ and $\mathrm{Cd}^{2+}$ ions using cyclic and differential pulse anodic stripping voltammetry. The possible mode of interaction of functional groups with metal ions is proposed based on the pKa values of the modifier functionalities present on the surface of graphitic carbon particles. The analytical utility of the proposed sensor has been validated by measuring the lead and cadmium content from pretreated waste water samples of lead acid batteries.
\end{abstract}

(ㄷ) 2012 Elsevier B.V. All rights reserved.

\section{Introduction}

Lead and cadmium are highly toxic metal ions which have been routinely discharged into the environment from metallurgical, electroplating, paper mill and fertilizer industries [1,2]. As a result of its high toxicity, exposure to these metal ions even at trace level may affect both mankind and aquatic systems [3]. The world health organization WHO has recommended threshold limit values TLV of $10 \mu \mathrm{g} \mathrm{L}^{-1}$ and $3 \mu \mathrm{g} \mathrm{L}^{-1}$ for $\mathrm{Pb}^{2+}$ and $\mathrm{Cd}^{2+}$ ions in drinking water, respectively [4,5]. In recent years, a significant focus has been given in controlling these pollutants and development of novel sensors for their quantification at trace level. Monitoring of trace quantities of lead and cadmium ions can be readily measured in the laboratory using spectroscopic techniques, but these are highly expensive, require skilled personal to operate, sophisticated devices and not appropriate for field detection [6]. Hence there is a need for the development of portable devices for field measurement study which gives reliable results at low concentration level. One such methodology which can be exploited to develop portable devices is electrochemical stripping technique which offers high sensitivity, selectivity and field applicability [7]. Initially the stripping voltammetry has been explored as a novel technique with the use of mercury based electrodes which were universally accepted due to its high hydrogen over potential, good reproducibility, high sensitivity and easy surface renewability $[8,9]$.

\footnotetext{
* Corresponding author. Tel.: +91 80 22961352; fax: +91 8022961331.

E-mail address: mprangachem@gmail.com (P. Malingappa).
}

In recent years the use of mercury based electrodes has been minimized due to its high toxicity [10]. Recent trend towards green chemistry protocol aims to reduce the toxic effects by replacing the toxic electrode materials with nontoxic materials. Various types of bismuth modified electrodes have been used recently in place of mercury due to its low toxicity, easy alloy formation ability and superior analytical response over mercury based electrodes [11]. But the bismuth modified electrodes can easily oxidized in presence of air causing relatively low chemical stability [12]. New alternative electrode materials for stripping analysis are still in demand to meet the growing needs of the market for on site environmental monitoring of trace heavy metal ions. Hence various carbon based electrode materials have been used with a great emphasis to increase the sensitivity and selectivity of the electrode materials toward particular analytes by modifying the surface with selective functionalities having potential affinity towards metal ions [13]. In this direction various types of carbon paste electrodes CPEs have been reported by incorporating selective indicator molecules containing selective functional moieties. However these electrodes are beneficial from the point of surface renewability but suffer from stability due to continuous leaching of modifier molecule during prolonged electrochemical measurements and also the presence of binder hinders the electrode kinetics which inturn limits the long term usage, storage and operational stability [3,14-20]. Hence there is a need to design a robust, stable and easily renewable surface electrodes with modifier molecules covalently attached to the carbon surface to control the leaching of modifier molecule into electrolyte. Covalent derivatization of carbon substrate prevents not only indicator leaching but also the use of binder. The absence 
of binder increases the long term storage stability of the fabricated electrodes and also improves the electrode kinetics.

The oxygen containing functionalities like carboxyl and hydroxyl groups are known to show potential affinity towards metal ions like lead and cadmium [21-23]. In the present study, we have used salicylic acid as a modifier molecule and covalently anchored onto the surface of graphitic carbon in bulk quantities through microwave irradiation. The modified graphitic carbon particles were used to fabricate binderless bulk modified electrode. These electrodes are new type of electrodes obtained by recompressing the covalently modified graphitic carbon particles at high pressure without using any binder. Till to date, there have been no reports on the covalent modification of graphitic carbon with salicylic acid as modifier molecule and the use of binderless bulk modified electrodes as metal ion sensors. Herein we have used these electrodes as electrochemical metal ion sensors and also explored the simultaneous determination of lead and cadmium ions at nanomolar levels with good reproducibility over a period of several months. Based on the surface $\mathrm{pKa}$ values of the modifier functionalities the possible mechanism of interaction of modifier functionalities with the given metal ions is also proposed. The analytical application of the developed sensor has been shown by determining the lead and cadmium ions from waste water samples of lead acid batteries.

\section{Experimental}

\subsection{Chemicals and reagents}

All reagents used were Analar grade and used without further purification. Graphite (dia. $>20 \mu \mathrm{m}$ ), 4-aminosalicylic acid and Potassium bromide for IR spectroscopy (FTIR grade, Purity 99\%) were obtained from Sigma-Aldrich. Acetic acid, sodium acetate and sodium hydroxide were purchased from SD Fine Chemicals, Mumbai. All $\mathrm{pH}$ solutions in the range $\mathrm{pH} 1-10$ were prepared using deionised water from MilliQ water purifier (Millipore, USA) with a resistivity of not less than $18.2 \mathrm{M} \Omega \mathrm{cm}^{-1}$ at $25^{\circ} \mathrm{C}$. Working standards of lead and cadmium ionic solutions were prepared using lead and cadmium nitrate salts.

\subsection{Apparatus}

All electrochemical measurements were carried out using electrochemical analyzer [CH Instruments, Texas, USA, model CHI 619B] at room temperature in an electrochemical cell of volume $10 \mathrm{~mL}$ with a standard three electrode configuration. Binderless bulk modified electrode (dia. $=5 \mathrm{~mm}$ ) acted as working electrode, $\mathrm{A}$ $\mathrm{Pt}$ (purity 99.99\%) wire as the counter electrode and $\mathrm{Ag} / \mathrm{AgCl}$ (3 M $\mathrm{KCl}$ ) as a reference electrode ( $\mathrm{CH}$ Instruments, Texas, USA). Before electrochemical measurements, the solutions were degassed using high purity nitrogen gas for $15 \mathrm{~min}$. All $\mathrm{pH}$ measurements were carried out using Control Dynamics pH meter (APX 175). Infrared spectrometric measurements were recorded using FTIR Shimadzu $8400 \mathrm{~S}$ in the range $1000-3600 \mathrm{~cm}^{-1}$ with a resolution of $4 \mathrm{~cm}^{-1}$. Scanning electron microscopy images were recorded using JEOL (JSM-840A) scanning electron microscope. Microwave experiments were conducted using domestic microwave oven.

\subsection{Analytical procedure}

The simultaneous determination of $\mathrm{Pb}^{2+}$ and $\mathrm{Cd}^{2+}$ ions were carried out using differential pulse anodic stripping voltammetry (DPASV) in the potential range from -1.0 to $0.0 \mathrm{~V}$ with an amplitude of $0.01 \mathrm{~V}$ and a pulse width of $0.05 \mathrm{~s}$. Known amounts of both lead and cadmium ions were taken in an electrochemical cell of $10 \mathrm{~mL}$ volume containing sodium acetate solution of $\mathrm{pH} 8$ which is fitted with a tab controlled magnetic stirrer. The fabricated electrode was immersed into the above stirred solution for 4 min to preconcentrate the metal ions at the interface by applying the reduction potential of $-0.8 \mathrm{~V}$. Then they were subsequently stripped off from the electrode surface into the bulk of the solution by scanning the potential in the positive direction after $15 \mathrm{~s}$ of equilibration time.

\subsection{Covalent modification of graphitic carbon particles with 4-aminosalicylic acid}

One gram of graphitic carbon particles were taken in $100 \mathrm{~mL}$ beaker containing $10 \mathrm{~mL}$ of conc. $\mathrm{HNO}_{3}$ and subsequently irradiated with microwave energy (15\% of total of $900 \mathrm{~W}$ ) for about 2 min to induce carboxylic groups on the surface of carbon substrate. Then $200 \mathrm{mg}$ ( $95 \mathrm{mM}$ ) of 4-aminosalicylic acid was added and irradiation was continued for $1 \mathrm{~min}$. The modified graphitic carbon particles were washed well with small quantities of acetonitrile several times to remove any unreacted and physisorbed modifier molecules. Then it was washed with ample quantities of distilled water to remove the acid present in the reaction mixture. Finally the carbon particles were washed with acetone to remove the moisture. The derivatized carbon particles were dried by placing it inside a fume hood for a period of $12 \mathrm{~h}$ and stored in an airtight container prior to its use [24]. The schematic representation of the covalent modification of the carbon has been shown in Scheme 1 .

\subsection{Fabrication of binderless, bulk modified electrode}

Electrodes were fabricated by using unmodified, oxidized and modified graphitic carbon particles. Initially about $150-200 \mathrm{mg}$ of carbon particles were taken and compressed in the form of pellets at a pressure of $6-8$ tons $\mathrm{cm}^{-2}$ for about $6 \mathrm{~h}$ without using any binder. The resistance of the pellets was measured and it was found to be $1 \Omega$ for unmodified, $1.36 \Omega$ for oxidized and $2 \Omega$ for modified electrode. In each case the compressed pellet was cut into small pieces of $5 \mathrm{~mm}$ diameter and mounted onto the one end of the Teflon tube with an external diameter of $8 \mathrm{~mm}$ and internal diameter of $5 \mathrm{~mm}$. A copper wire was used for electrical contact and silver paste serves as the conducting medium between the pellet and the copper wire. The other end of the Teflon tube has been sealed with araldite. Then the surface of the electrode was polished with 600 and 1500 grit emery sheets followed by $4 / 0,5 / 0$ and 6/0 emery polishing papers to obtain a smooth surface before its use. Roughness on this electrode surface was created by scratching the electrode surface against emery sheets in unidirection for the reproducible results. The schematic representation of fabrication of electrode and the plausible mechanism of its interaction with metal ions is shown in Scheme 2.

\subsection{Determination of $\mathrm{pKa}$ and degree of functionalization}

Boehm titration method was used to determine the $\mathrm{pKa}$ value of the surface functional groups present on the carbon particles as well as the degree of functionalization of the modified carbon particles. The titration was carried out by treating a known weight of modified carbon particles with excess of $0.01 \mathrm{M}$ solution of $\mathrm{NaOH}$ in a conical flask and titrating the unreacted base against $0.01 \mathrm{M} \mathrm{HCl}$. After the addition of each increment of acid the solution was stirred for $30 \mathrm{~s}$ and the $\mathrm{pH}$ of the resulting solution was measured using $\mathrm{pH}$ meter. This method has been used to determine the $\mathrm{pKa}$ value of modifier molecules present on the surface of graphitic carbon. Similarly a blank titer value was measured using native graphitic carbon particles. The degree of functionalization of carbon substrate material was calculated using sample and blank titer values [25-27]. 


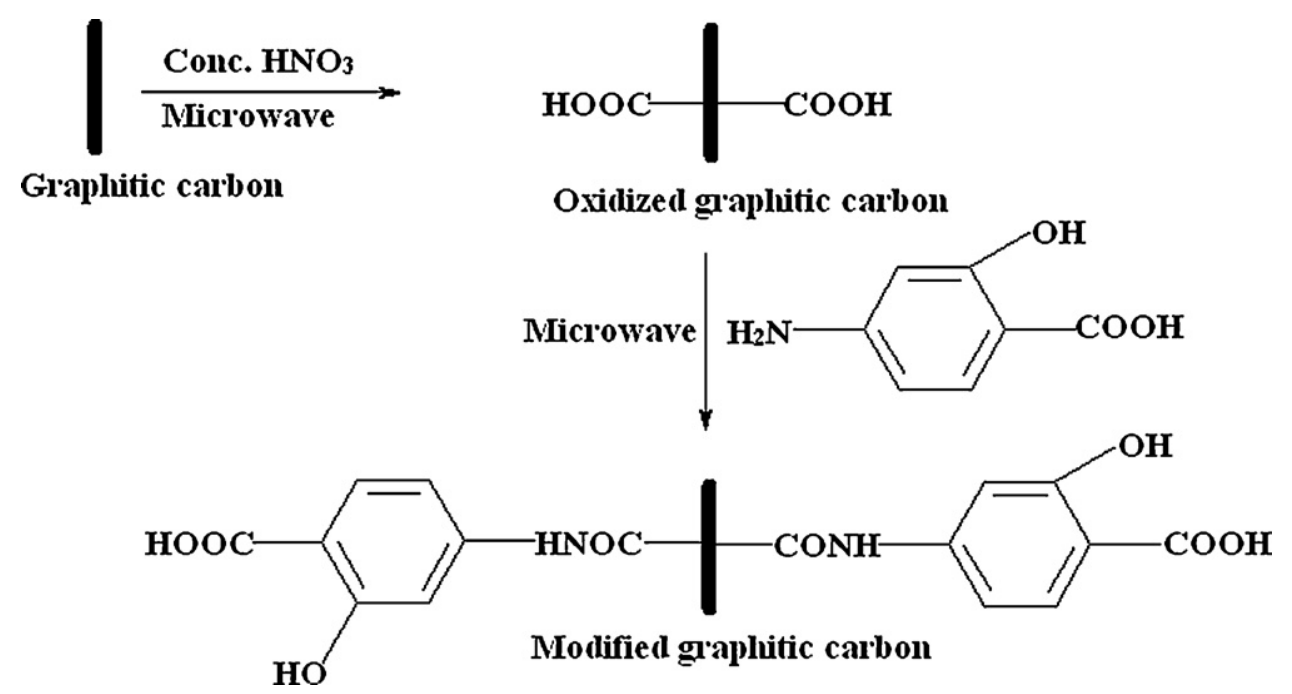

Scheme 1. Schematic representation of microwave assisted covalent bulk modification of graphitic carbon with 4-aminosalicylic acid.

\section{Results and discussion}

\subsection{Surface morphology of modified graphitic carbon}

The scanning electron microscopy (SEM) images of the modified and native graphitic carbon particles have been recorded after immobilizing them on a conducting strip (figures not shown). The images have revealed that there are no significant morphological changes between the modified graphitic carbon particles and its underivatized counter parts.

\subsection{Infrared spectroscopic characterization}

The Fourier transform infrared (FTIR) spectra of 4-aminosalicylic acid, modified and unmodified graphitic carbon particles were recorded and compared to confirm the covalent attachment of modifier molecules on the surface of carbon (Fig. 1). The samples were uniformly mixed with $\mathrm{KBr}$ in the ratio $1: 100$ to make a thin and transparent pellet. The spectrum of the unmodified carbon (Fig. 1A) showed bands at 1352,1593 and $2815 \mathrm{~cm}^{-1}$ which corresponds to the stretching frequencies of $\mathrm{C}-\mathrm{C}, \mathrm{C}=\mathrm{C}$ and aromatic protons, respectively. The peak at $3423.34 \mathrm{~cm}^{-1}$ might be due to the $-\mathrm{OH}$ stretching. The spectrum of 4-aminosalicylic acid (Fig. 1B) revealed the presence of $\mathrm{C}-\mathrm{O}, \mathrm{C}-\mathrm{OH}$ stretching and $\mathrm{C}-\mathrm{OH}$ deformation of phenolic group peaks at 1133,1290 and at $1427 \mathrm{~cm}^{-1}$, respectively. The presence of peaks at 1675,3465 and $3357 \mathrm{~cm}^{-1}$ clearly indicated the presence of $-\mathrm{C}=\mathrm{O},-\mathrm{C}-\mathrm{OH}$ and aromatic primary amine respectively.

The spectrum of salicylic acid modified graphitic carbon particles has showed the presence of $\mathrm{C}-\mathrm{O}, \mathrm{C}-\mathrm{OH}$ stretching and

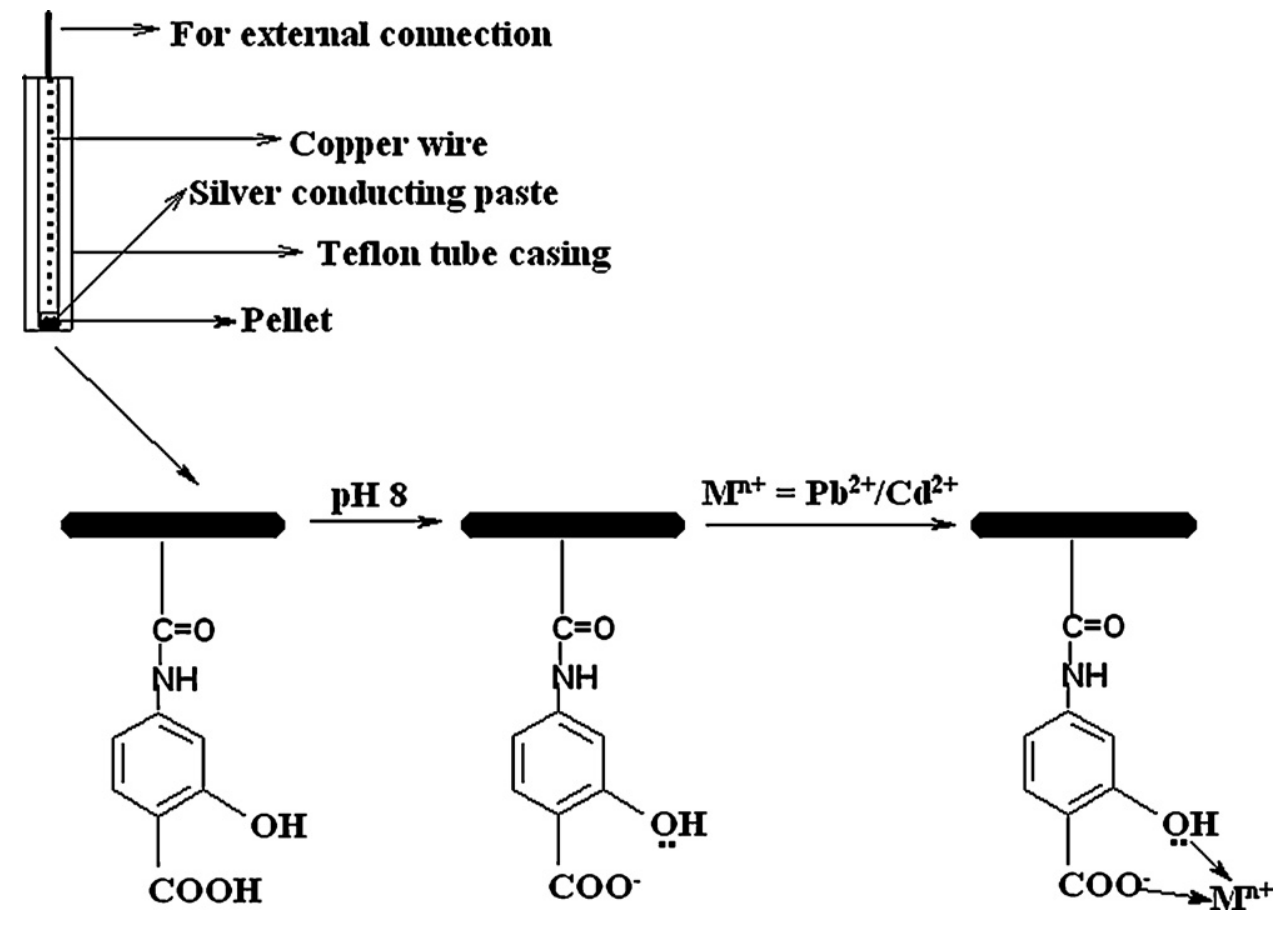

Scheme 2. Schematic representation of electrode fabrication and its plausible interaction with metal ions. 


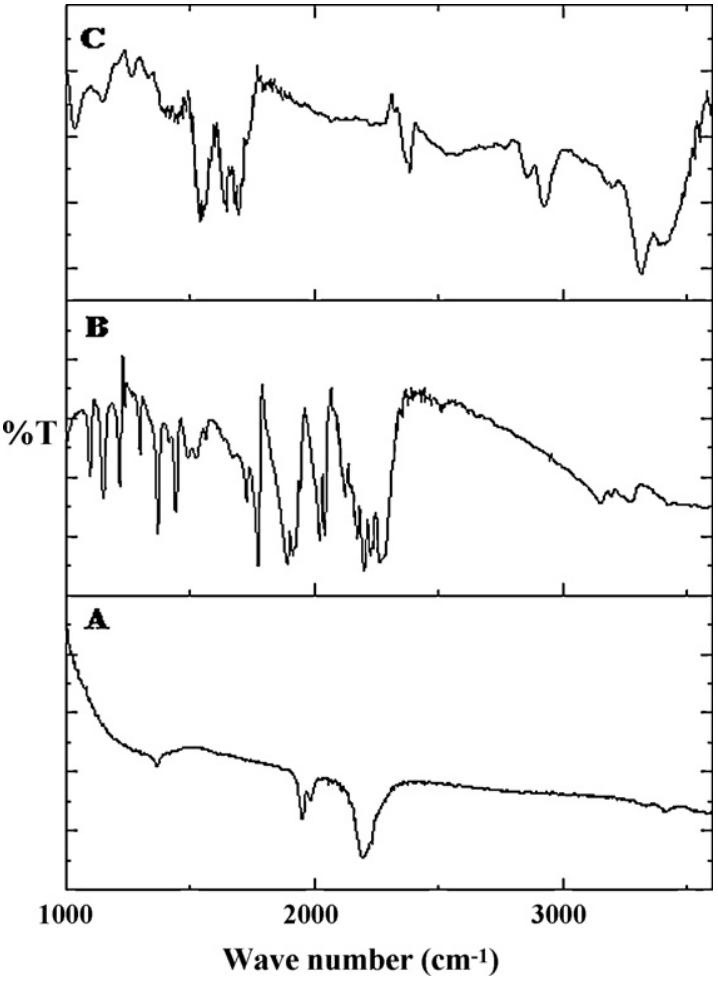

Fig. 1. FTIR spectra of native carbon (A), 4-aminosalicylic acid (B) and modified graphitic carbon $(C)$

$\mathrm{C}-\mathrm{OH}$ deformation of phenolic group peaks at 1050, 1226 and at $1440 \mathrm{~cm}^{-1}$ respectively (Fig. $1 \mathrm{C}$ ). It also indicated the presence of $-\mathrm{C}=\mathrm{O}$ and $-\mathrm{OH}$ stretching of carboxyl groups through the peaks at 1700 and $3410 \mathrm{~cm}^{-1}$. The peaks at 1647.4 and $3313.4 \mathrm{~cm}^{-1}$ has revealed the presence of $-\mathrm{C}=\mathrm{O}$ and $-\mathrm{NH}$ groups of amide bond, which were not found in the spectra of unmodified carbon as well in the 4-aminosalicylic acid [28,29]. All these studies have revealed that the carbon particle surface contains salicylic acid groups and derivatization process has yielded covalent attachment of modifier molecules.

\subsection{Determination of pKa values of modified graphitic carbon and degree of functionalization}

The $\mathrm{pKa}$ values of salicylic acid in solution, oxidized graphitic carbon and salicylic acid modified graphitic carbon have been studied according to Boehm's method [25]. The titration curves showed two distinct deflection points which indicates the presence of two types of functional groups (data not shown). The $\mathrm{pKa}$ values for salicylic acid in solution are found to be 4.8 and 11.2 since the carboxylic group is more acidic than the phenolic group the $\mathrm{pKa}$ value of 4.8 is attributed to the carboxylic acid group and 11.2 is attributed to hydroxyl group of the salicylic acid. Next we measured the $\mathrm{pKa}$ values for oxidized and modified carbon. The oxidized carbon showed pKa values as 4.5 and 11.6 for carboxyl and hydroxyl groups respectively, where as the modified graphitic carbon particles showed pKa values of carboxylic groups and hydroxyl groups of the salicylic acid as 6.1 and 11.3, respectively. In case of modified graphitic carbon, the $\mathrm{pKa}$ value of carboxylic group is in agreement with the literature [30]. The degree of functionalization of the modified graphitic carbon has been calculated based on the volume of the acid consumed for the sample and blank titrations. The volume difference of the $\mathrm{HCl}$ consumption for the blank and sample was calculated and translated into its equivalent. The degree of functionalization has been expressed in millimoles of acidic groups

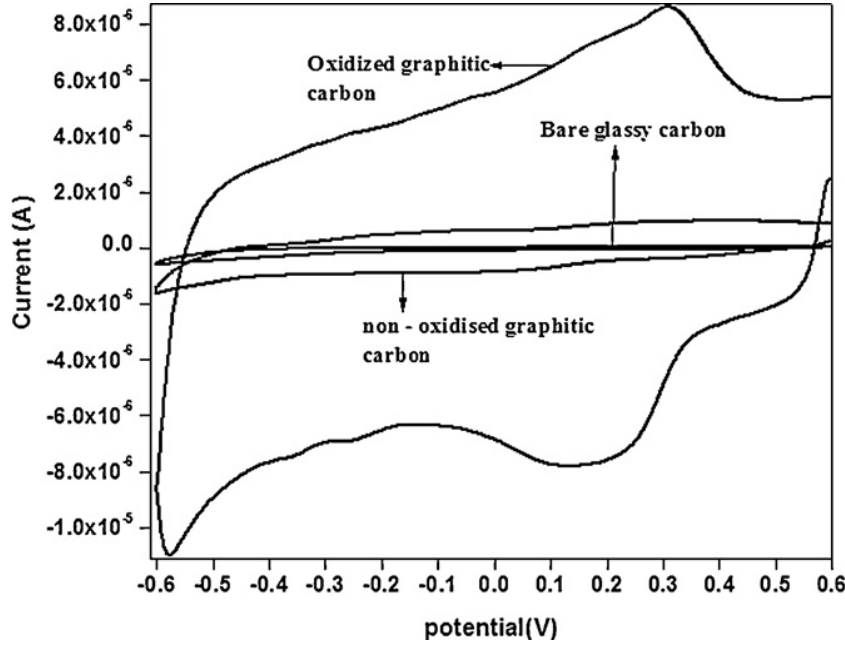

Fig. 2. Overlaid voltammograms of glassy carbon electrode immobilized with nonoxidized and oxidized graphitic particles in an acetate buffer of $\mathrm{pH} 4$ containing $0.1 \mathrm{M} \mathrm{KCl}$ as supporting electrolyte, scan rate $-50 \mathrm{mV} \mathrm{s}^{-1}$.

per $g$ of modified carbon particles and it was calculated using the following formula [27].

$C=\frac{\left[2.43(b-a) \mathrm{M}_{\mathrm{HCl}}\right]}{m(\text { modified carbon })}$

where $a$ and $b$ are the volumes of $\mathrm{HCl}$ consumed for the titration of sodium hydroxide containing modified carbon and unmodified carbon (blank) respectively. $\mathrm{MHCl}$ is the molarity of the $\mathrm{HCl}$ solution and $\mathrm{m}_{\text {(modified carbon) }}$ is the mass of modified carbon used in the titration. The degree of functionalization has been found to be $2.61 \mathrm{mM} \mathrm{g}^{-1}$ (3.07\%) of graphitic carbon.

\subsection{Electrochemical characterization of oxidized graphitic carbon}

Graphitic carbon particles were oxidized under microwave irradiation to introduce oxygen containing functionalities like carboxylic groups due to easy amenability for further modification with terminal amine containing molecules. The cyclic voltammetric behavior of native and carboxylic group modified graphitic carbons were studied in order to confirm the presence of carboxylic acid groups anchored on the graphitic carbon surface during microwave assisted oxidation process. This process was carried out by physically immobilizing them onto the surface of glassy carbon electrode (GCE) and studying their electrochemical behavior. The cyclic voltammograms were recorded in sodium acetate buffer solution of $\mathrm{pH} 4$ containing $0.1 \mathrm{M} \mathrm{KCl}$ as supporting electrolyte in the potential range +0.6 to $-0.6 \mathrm{~V}$ with a scan rate of $50 \mathrm{mV} \mathrm{s}^{-1}$ (Fig. 2).

In the forward scan, the glassy carbon electrode modified with oxidized graphitic carbon particles showed a reductive peak at $0.216 \mathrm{~V}$ and in the subsequent reverse scan an oxidative peak was observed at $0.312 \mathrm{~V}$. The bare electrode and the modified one with non-oxidized graphitic carbon particles did not show any redox peaks in the potential region studied. This kind of redox behavior of the oxidized carbon is in agreement with the literature and attributed to the redox process of quinone like species formed during the oxidation process along with carboxylic groups [31]. All these observations have revealed the formation of oxygen containing functionalities on the carbon surface during oxidation process through microwave irradiation. 


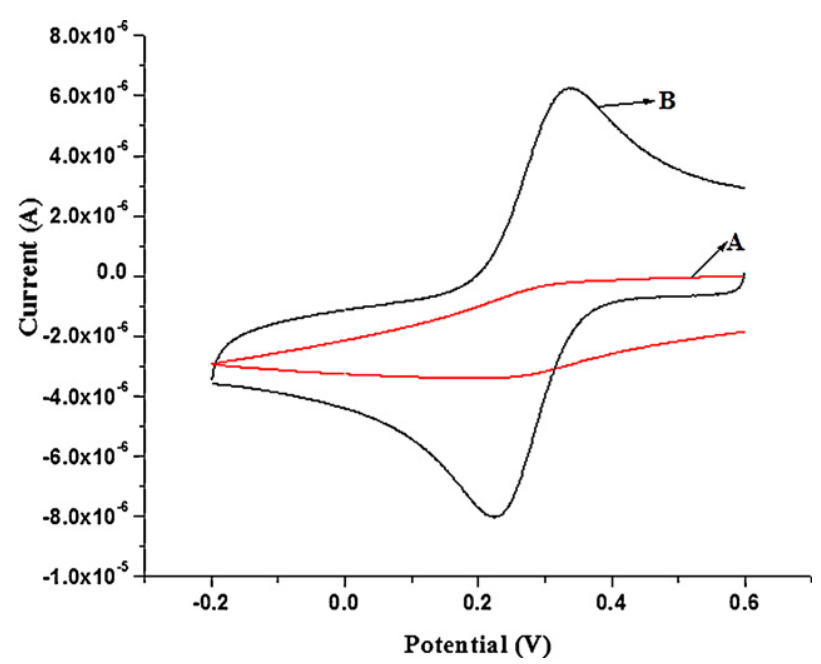

Fig. 3. Cyclic voltammograms of $5 \mathrm{mM}$ of $\mathrm{K}_{3}\left[\mathrm{Fe}(\mathrm{CN})_{6}\right]$ at modified $(\mathrm{A})$ and unmodified (B) electrode in sodium acetate solution of $\mathrm{pH} 8$. Scan rate $-50 \mathrm{mV} \mathrm{s}^{-1}$.

\subsection{Electrochemical characterization of modified graphitic carbon}

Covalently modified graphitic carbon particles were electrochemically characterized in order to check the blocking effect of the modifier present on the carbon surface using standard redox system $\mathrm{K}_{3}\left[\mathrm{Fe}(\mathrm{CN})_{6}\right.$ ] [32]. The salicylic acid modified electrode contains functional groups like- $\mathrm{COOH}$ and-OH groups with fixed charge density depending upon the solution $\mathrm{pH}$. The cyclic voltammogram of $5 \mathrm{mM} \mathrm{K}_{3}\left[\mathrm{Fe}(\mathrm{CN})_{6}\right]$ in an sodium acetate solution of $\mathrm{pH} 8$ at unmodified electrode showed reversible redox couple for the standard redox system. However the reversibility was almost suppressed at modified graphitic carbon (Fig. 3). This is due to the deprotonation of carboxylic groups at working $\mathrm{pH}$ condition ( $\mathrm{pKa}$ value of carboxylic acid group of the modifier is 6.1). However the hydroxyl groups are still undissociated at this $\mathrm{pH}$ value (hydroxyl group pKa value is 11.3). Based on these studies, we can ascertain that the behavior of modified carbon with respect to the standard system may be attribute to the presence of electrostatic repulsion between the negatively charged electrode surface $\left(-\mathrm{COO}^{-}\right.$group and the lone pair of electrons on the oxygen atom of the-OH group) and the negatively charged coordination sphere of the standard system.

\subsection{Voltammetry of $\mathrm{Pb}^{2+}$ and $\mathrm{Cd}^{2+}$ ions at salicylic acid modified electrode}

The electrochemical response of the unmodified, modified and oxidized electrodes toward lead and cadmium ions were initially examined using cyclic voltammetry. Typical cyclic voltammetric responses of the lead and cadmium ions in sodium acetate solution of $\mathrm{pH} 8$ were given in Fig. 4. In case of modified electrode, the cyclic voltammogram showed two peaks at -0.67 and $-0.87 \mathrm{~V}$ in the reductive scan which might be attributed to the reduction of lead and cadmium ions respectively. However in the subsequent reverse scan, the voltammogram showed two peaks at -0.49 and $-0.75 \mathrm{~V}$ which corresponds to the reoxidation of lead and cadmium ions, respectively. The redox potential of $\mathrm{Pb}^{2+}$ is in agreement with the literature [21] and the peaks at -0.87 and $-0.75 \mathrm{~V}$ might be due to the reduction and oxidation of $\mathrm{Cd}^{2+}$ ions, respectively. In case of oxidized and modified electrode there is a small increase in the capacitive current when compared to unmodified electrode. The increased capacitive current may be attributed to the change in the interfacial structure after modification and also due to the

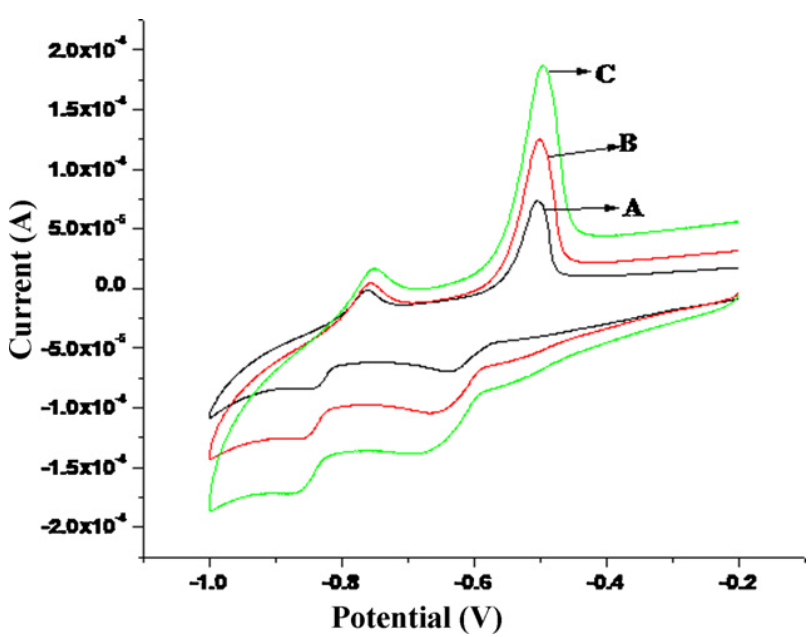

Fig. 4. Cyclic voltammograms of $10 \mathrm{mM}$ each of lead and cadmium at bare (A), oxidized (B) and modified (C) electrodes in sodium acetate solution of $\mathrm{pH} 8$. Scan rate $-50 \mathrm{mVs}^{-1}$.

uneven exposure of the number of carbon atoms at the interface since the electrodes were physically constructed and the surface was renewed by simple mechanical polishing using emery sheets of different grades. The faradic current for the oxidation of metal ions is higher at modified electrode when compared to unmodified and oxidized carbon electrodes. These observations have revealed that the presence of modifier molecule with suitable functionalities could enhance the electrochemical response for both lead and cadmium ions. This kind of modified electrode behavior might be attributed to the interacting ability of the functional groups i.e., carboxyl and hydroxyl present on the surface of carbon toward lead and cadmium ions present in the electrolyte at the interface [21].

\subsection{Differential pulse anodic stripping voltammetry of $\mathrm{Pb}^{2+}$ and $\mathrm{Cd}^{2+}$ at modified electrode}

The oxidation peaks for both $\mathrm{Pb}^{2+}$ and $\mathrm{Cd}^{2+}$ ions are larger and sharper than the reduction peaks at both native and modified carbon electrodes (Fig. 4). Hence the anodic peaks were systematically studied by differential pulse anodic stripping voltammetry (DPASV) which gave better sensitivity than cyclic voltammetry $[8,9]$. The

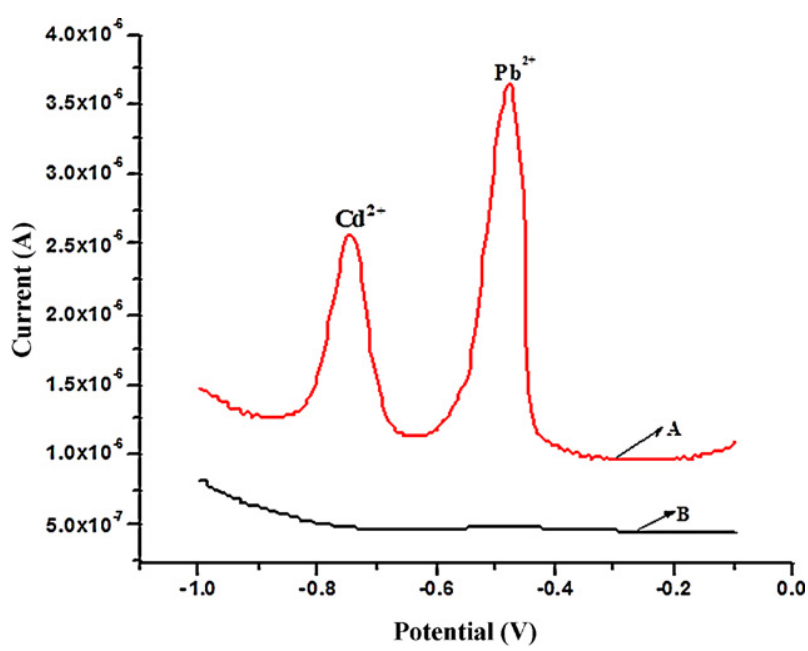

Fig. 5. Differential pulse anodic stripping voltammograms of lead and cadmium ions $(200 \mathrm{nM})$ in a sodium acetate solution of $\mathrm{pH} 8$. (A) in presence of metal ions and (B) in the absence of metal ions. Preconcentration time $=4 \mathrm{~min}$. Preconcentration potential $=-0.8 \mathrm{~V}$. 

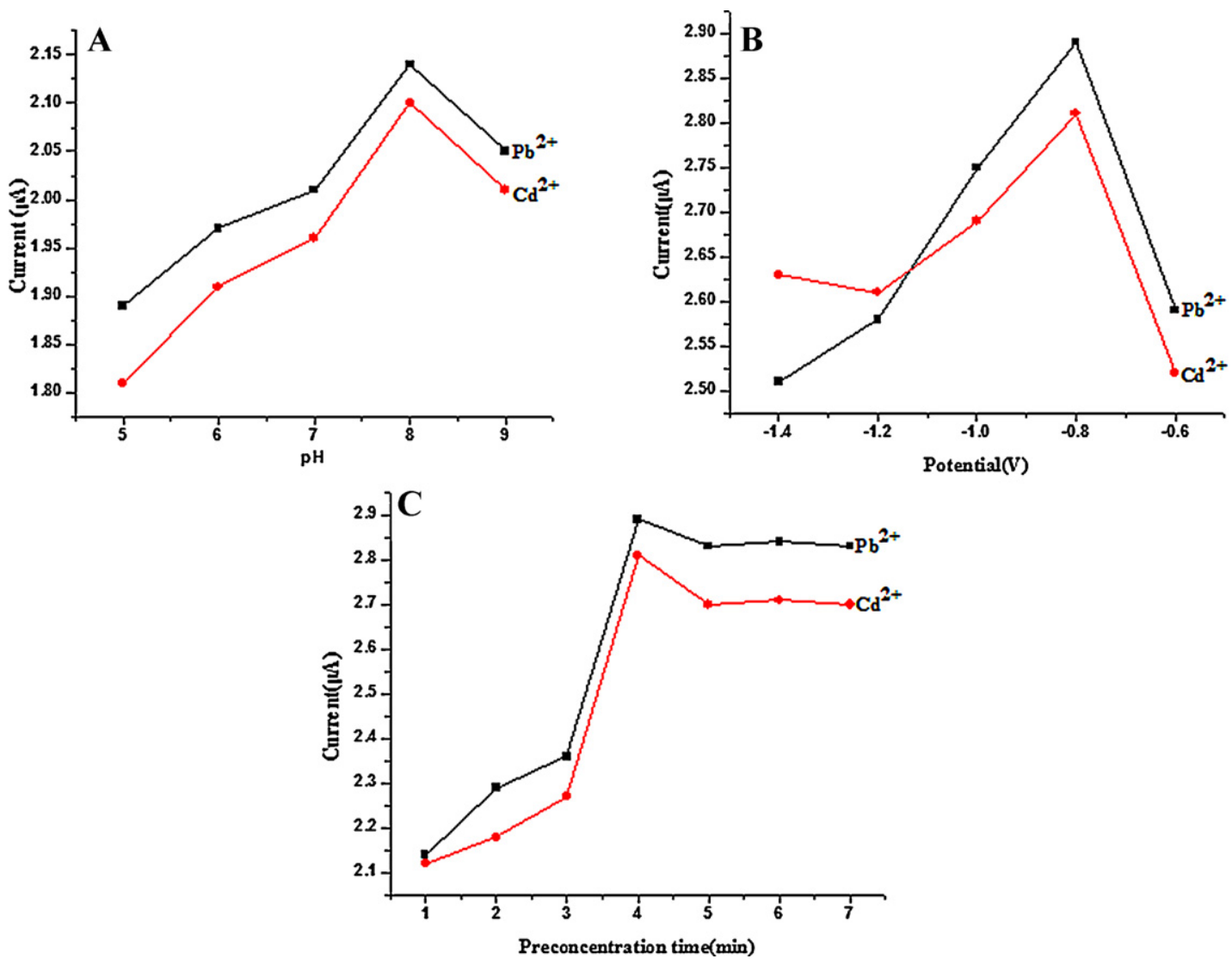

Fig. 6. Optimization study, (A) effect of pH, (B) preconcentration potential, (C) preconcentration time. Concentration - $200 \mathrm{nM}$ each of lead and cadmium.

differential pulse anodic stripping voltammetry in the absence and in presence of lead and cadmium ions in sodium acetate solution of $\mathrm{pH} 8$ were studied in the potential range -1.0 to $0.0 \mathrm{~V}$ (Fig. 5 ).

In the absence of metal ions, the modified electrodes did not show any stripping peaks in the potential region -1.0 to $0.0 \mathrm{~V}$. Therefore the modified electrode can be applied for the quantification of analytes (metal ions) which are active in this potential region. In presence of metal ions, the voltammograms clearly showed well defined stripping (oxidation) peaks for cadmium at $-0.78 \mathrm{~V}$ and lead at $-0.52 \mathrm{~V}$ with a peak to peak separation of $260 \mathrm{mV}$. This separation between DPV peaks is large enough and hence simultaneous determination of lead and cadmium metal ions were studied using the modified electrode. Since the working $\mathrm{pH}$ is 8 , the carboxylic groups of the modifier molecules are expected to be deprotonated and the hydroxyl groups are still undissociated. Hence the voltammetric behavior of the metal ions at modified electrode might be attributed to the complexing ability of the modifier functionalities such as carboxylate and the lone pair of electrons present on the oxygen atom of the hydroxyl groups at the electrode interface (Scheme 2). This kind of interaction may pose effective chelation with enhanced coordination which may provide lower detection limits. The complexation behavior of metal ions at the interface and the possible mechanism of preconcentration as well as stripping steps are given as below $[21,33]$.

I. Preconcentration and complexation step $\left(\mathrm{M}=\mathrm{Pb}^{2+}\right.$ and $\left.\mathrm{Cd}^{2+}\right)$

$\mathrm{M}^{2+}+2 \mathrm{HL} \rightarrow \mathrm{ML}_{2}+2 \mathrm{H}^{+}$

where HL represents the ligands present on the surface of graphitic carbon such as $-\mathrm{COOH}$ and $-\mathrm{OH}$ groups.

$\mathrm{ML}_{2}+2 \mathrm{H}^{+}+2 \mathrm{e}^{-} \rightarrow \mathrm{M}+2 \mathrm{HL}$

\section{Stripping step}

$\mathrm{M} \rightarrow \mathrm{M}^{2+}+2 \mathrm{e}^{-}$

\subsection{Optimization study}

The analytical parameters like $\mathrm{pH}$, deposition potential and deposition time which influence the analytical response of the modified electrode were optimized in order to achieve the maximum efficiency of the developed sensor toward the metal ion quantification at trace level concentration.

The interaction of modifier molecule with the metal ions is an interfacial process which mainly depends on the nature of the functionalities which inturn depend on the $\mathrm{pH}$ of the bulk solution as well as $\mathrm{pKa}$ value of the surface functional moieties. The $\mathrm{pKa}$ values of carboxylic and hydroxyl groups of the modifier molecule were found to be 6.1 and 11.3 respectively. The carboxylic groups are protonated in acidic $\mathrm{pH}$ and expected to be deprotonated in neutral and in alkaline medium. Hence the effect of pH plays a key role in determining the metal ions. Hence the effect of $\mathrm{pH}$ on the accumulation of metal ions was studied in the $\mathrm{pH}$ range $1-10$. The measurements were carried out using various buffers like acetate, phosphate, ammonia-ammonical buffers, borate buffers and $\mathrm{pH}$ solutions like sodium acetate solutions of desired $\mathrm{pH}$ values. Among all these, sodium acetate solution with a $\mathrm{pH} 8$ resulted well defined stripping peaks for both lead and cadmium ions with a considerable peak to peak separation hence it has been chosen as best $\mathrm{pH}$ solution for analysis. The charge density on the modifier molecule mainly depends on the solution $\mathrm{pH}$, therefore the effect of $\mathrm{pH}$ value of the sodium acetate solution on the stripping response was studied (Fig. 6A). 
No analytical response was observed in the $\mathrm{pH}$ range $1-4$ for both the metal ions which revealed the absence of interaction of modifier functionalities with the metal ions at the interface. In acidic condition, the lone pair of electrons present on the oxygen atom of the modifier functionalities may get protonated. Due to this, the surface of the modified electrode acquires positive charge and hence it repels the positively charged metal ions at the interface. The peak currents increases from 5 to 8 and then it starts decreases. The increase of peak current is due to the deprotonation of more and more carboxylic group present on the electrode surface and the availability of lone pair of electrons on the oxygen atom of the hydroxyl group of the modifier molecule to interact with metal ions. Generally lead and cadmium ions may undergo precipitation in slight alkaline conditions. However the precipitation is not observed in the present studies because the metal ions were added into the electrochemical cell just before the analysis. It is well known that the acetate ions form weak complexes with these metal ions and prevent their precipitation [33,34]. Hence sodium acetate solution of $\mathrm{pH} 8$ was used as an optimum $\mathrm{pH}$ in all further studies.

Next, the influence of deposition potential on the stripping response of lead and cadmium ions were studied (Fig. 6B). The deposition potential was varied between -0.6 and $-1.4 \mathrm{~V}$ under optimized $\mathrm{pH}$ condition. The stripping response increased remarkably from -0.6 to $-0.8 \mathrm{~V}$ then as the deposition potential become more positive than $-0.8 \mathrm{~V}$, the peak currents decreases due to the reduction of other chemicals at these potentials and interfere in the determination of lead and cadmium ions. Hence in all further studies $-0.8 \mathrm{~V}$ was used as an optimum deposition potential [16].

The effect of deposition time on the stripping response for both the lead and cadmium ions were illustrated in Fig. 6C. The peak currents for both $\mathrm{Pb}^{2+}$ and $\mathrm{Cd}^{2+}$ ions were studied from 1 to $7 \mathrm{~min}$ and it has been found that the peak current increases with increase of preconcentration time from 1 to $4 \mathrm{~min}$. This is due to the fact that longer the preconcentration time more and more analytes get accumulated with the surface functionalities at the electrode/solution interface, hence current increases. After $4 \mathrm{~min}$, the peak current becomes almost constant due to either surface saturation or the attainment of equilibrium between the complexed metal ions and the ions in solution [16]. Therefore a preconcentration time of $4 \mathrm{~min}$ has been used in all further studies.

\subsection{Analytical merits}

The calibration plot was constructed after the successive additions of $100 \mathrm{nM}$ each of lead and cadmium ions into an electrochemical cell of $10 \mathrm{~mL}$ volume containing sodium acetate solution of $\mathrm{pH}$ 8. The peak currents increased linearly with increase of both lead and cadmium ions concentration in the range $100-800 \mathrm{nM}$ (Fig. 7) with a detection limit ( $3 \sigma$ ) of 0.9 and $0.7 \mathrm{nM}$, respectively. These detection limits are well below the prescribed maximum threshold limit values recommended by world health organization $[4,5]$. The proposed electrode has showed excellent stability, wide linear range, low detection limit, long term storage and reproducible analytical performance. The analytical performance of the proposed sensor electrode has been compared with other carbon electrodes (Table 1). The proposed sensor electrode can be used as an alternative to the existing sensors in industrial atmospheres for routine monitoring of toxic metal ions at trace level.

\subsection{Interference study}

Precise and selective determination of lead and cadmium ions in real sample is a challenging task, as the other metal ions commonly

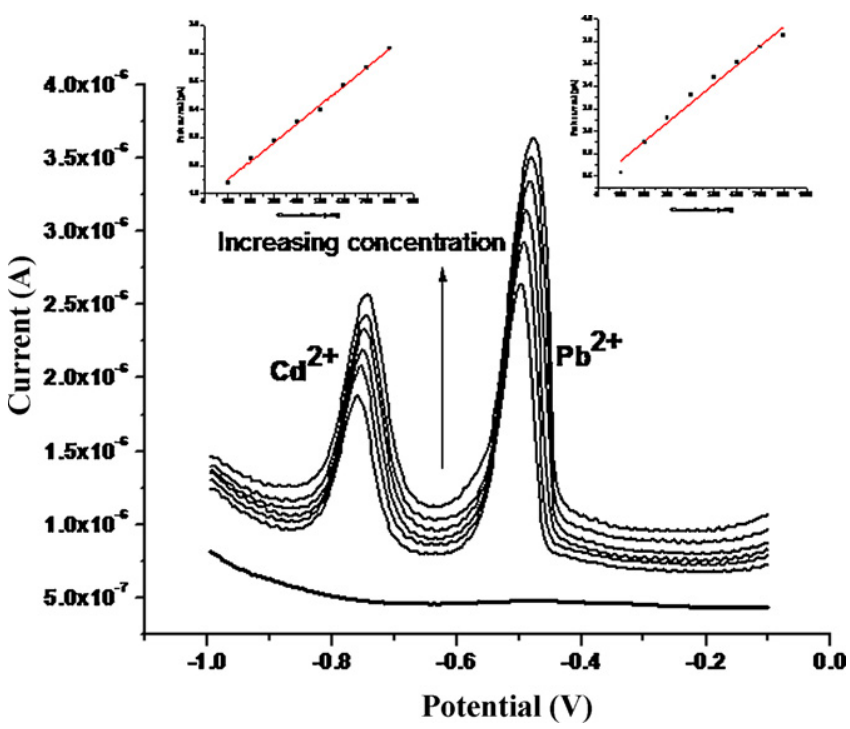

Fig. 7. Overlaid differential pulse anodic stripping voltammograms (inset: calibration plots).

Table 1

Comparison of some of the modified carbon electrodes reported for the simultaneous determination of $\mathrm{Pb}^{2+}$ and $\mathrm{Cd}^{2+}$ ions using differential pulse anodic stripping voltammetry (DPASV).

\begin{tabular}{|c|c|c|c|}
\hline \multirow[t]{2}{*}{ Modified carbon electrodes } & \multicolumn{2}{|c|}{$\begin{array}{l}\text { Limit of detection } \\
\text { (LOD)/nM }\end{array}$} & \multirow[t]{2}{*}{ Reference } \\
\hline & $\mathrm{Pb}^{2+}$ & $\mathrm{Cd}^{2+}$ & \\
\hline Barium hydrogen phosphate - CPE & 3 & 5 & [15] \\
\hline Diacetyldioxime - CPE & 10 & 40 & [35] \\
\hline MWCNT - GC thin film & 4 & 6 & [36] \\
\hline $\begin{array}{l}\text { Clay nanoparticle-anthraquinone - } \\
\text { GC thin film }\end{array}$ & 1 & 3 & [37] \\
\hline $\mathrm{Cu}-\mathrm{DPABA}$ complex - GC & 1.9 & 1.2 & {$[38]$} \\
\hline Proposed sensor electrode & 0.9 & 10.7 & Present study \\
\hline
\end{tabular}

CPE: carbon paste electrode; MWCNT: multiwalled carbon nanotubes; GC: glassy carbon; DPABA: methyl 3,5-bis\{bis-[(pyridin-2-yl)methyl]amino\}methylbenzoate); DPASV: differential pulse anodic stripping voltammetry.

present in the samples may also get deposited and stripped off under the same optimized conditions used in the detection of lead and cadmium ions. In order to examine the analytical performance of the proposed sensor electrode toward lead and cadmium quantification in presence of commonly existing cations and anions, the measurements have been performed using $300 \mathrm{nM}$ of each of lead and cadmium ions in presence of different concentrations of common ions. The corresponding tolerance limits for different cations and anions were listed in Table 2. Above the tolerance limit the added ions interfere and alter the peak currents produced by the oxidation of lead and cadmium ions. The developed sensor has showed least interference from most of the common ions due to

Table 2

Interference study.

\begin{tabular}{lc}
\hline Interfering ions & Tolerance \\
& limit (nM) \\
\hline $\mathrm{NH}_{4}{ }^{+}, \mathrm{Ba}^{2+}, \mathrm{Mg}^{2+}, \mathrm{Ca}^{2+}, \mathrm{Cl}^{-}, \mathrm{F}^{-}, \mathrm{PO}_{4}{ }^{3-}, \mathrm{SO}_{4}{ }^{2-}, \mathrm{K}^{+}, \mathrm{Mn}^{2+}, \mathrm{Li}^{+}, \mathrm{Ag}^{+}$ & 10,000 \\
$\mathrm{Co}^{2+}, \mathrm{C}_{2} \mathrm{O}_{4}{ }^{2-}, \mathrm{CO}_{3}{ }^{2-}$ & 1100 \\
$\mathrm{Hg}^{2+}, \mathrm{Bi}^{2+}, \mathrm{Sn}^{2+}, \mathrm{Fe}^{3+}$ & 900 \\
$\mathrm{Cu}^{2+}, \mathrm{Ni}^{2+}$ & 500 \\
\hline
\end{tabular}


Table 3

Determination of lead and cadmium from pretreated waste water samples of lead acid battery.

\begin{tabular}{|c|c|c|c|c|c|c|c|c|c|c|c|c|}
\hline \multirow[t]{3}{*}{ Sample } & \multicolumn{2}{|c|}{ Originally found (nM) } & \multicolumn{2}{|c|}{ Added (nM) } & \multicolumn{4}{|c|}{ Total (nM) } & \multicolumn{4}{|c|}{ Recovery (\%) } \\
\hline & \multirow[t]{2}{*}{$\mathrm{Pb}^{2+}$} & \multirow[t]{2}{*}{$\mathrm{Cd}^{2+}$} & \multirow[t]{2}{*}{$\mathrm{Pb}^{2+}$} & \multirow[t]{2}{*}{$\mathrm{Cd}^{2+}$} & \multicolumn{2}{|c|}{ Proposed method } & \multicolumn{2}{|c|}{ AAS method } & \multicolumn{2}{|c|}{ Proposed method } & \multicolumn{2}{|c|}{ AAS method } \\
\hline & & & & & $\mathrm{Pb}^{2+}$ & $\mathrm{Cd}^{2+}$ & $\mathrm{Pb}^{2+}$ & $\mathrm{Cd}^{2+}$ & $\mathrm{Pb}^{2+}$ & $\mathrm{Cd}^{2+}$ & $\mathrm{Pb}^{2+}$ & $\mathrm{Cd}^{2+}$ \\
\hline$A^{a}$ & 210.3 & ND & 200 & 200 & 410.1 & 190.10 & 400.9 & 190.7 & 99.51 & 95.50 & 99.03 & 98.50 \\
\hline $\mathrm{B}^{\mathrm{a}}$ & 270.9 & ND & 200 & 200 & 470.4 & 200.10 & 470.2 & 190.6 & 98.95 & 100.50 & 98.53 & 98.00 \\
\hline
\end{tabular}

ND: not detected.

a Samples were collected from different sources.

specific and selective interaction of the modifier functionalities with lead and cadmium ions.

\subsection{Surface renewability and long term storage stability}

The surface renewability of the fabricated electrode is an important parameter for repetitive and precise measurements. It was checked by determining the lead and cadmium ions using 10 fresh renewed surfaces in presence of $200 \mathrm{nM}$ of each lead and cadmium ions. The relative standard deviation in current response has been found to be $\pm 4 \%$, which indicates that the surface renewability of the electrode did not affect the electrochemical response but it confirms that the bulk modification is uniform throughout the matrix, hence a single electrode of this type can be used and reused for several measurements with same electrochemical performance. For long term analytical applications the developed electrodes should meet long term storage stability. The conventional carbon paste electrodes are generally prepared by using non conducting binders like nujol, paraffin, epoxy resin. The presence of these binders undoubtedly poses the extra charge transfer barrier wherein it decreases the electrode kinetics which inturn limits its long term storage stability. In addition to this, carbon paste electrodes suffer from leaching of modifier into electrolyte which limits the reproducibility of analytical responses which are not desirable in the routine analysis. In this direction, the long term stability of the developed sensor has been demonstrated over a period of 6 months (Fig. 8). In all these experiments the magnitude of stripping currents for both lead and cadmium ions has been found well below $\pm 10 \%$. This demonstrates the long term storage stability of the fabricated electrode hence these electrodes can be used for the precise measurement of metal ions over a period of several months. This kind of modified electrode can be used for long term industrial applications.

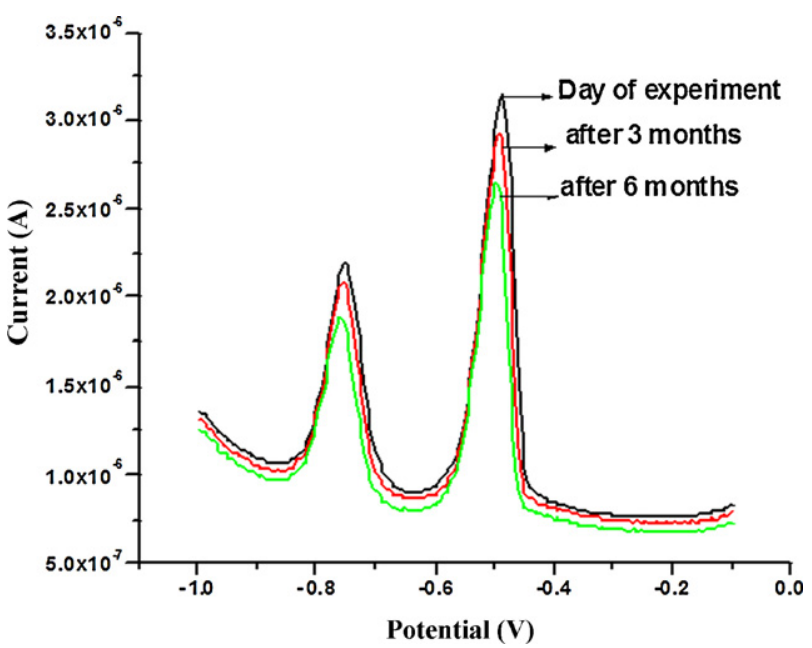

Fig. 8. Long term storage stability of the proposed sensor electrode over a period of six months.

\subsection{Application study}

In order to validate the developed sensor for industrial applications, lead and cadmium ions present in the pretreated waste water samples of lead acid battery have been determined. The pretreated samples were collected from two different battery sources and filtered through whatman filter paper (42 grade) to remove all the suspended particulate matter. Then $25 \mathrm{~mL}$ of the filtrate was used for analysis by adjusting the $\mathrm{pH}$ to 8 and diluting it to $100 \mathrm{~mL}$ From this diluted solution, $10 \mathrm{~mL}$ aliquot was taken in the electrochemical cell and analyzed according to the procedure described earlier (analytical procedure). The results obtained by the proposed electrode are in good agreement with the results obtained by AAS method (Table 3 ). The proposed sensor showed a linearity in the concentration range $100-800 \mathrm{nM}$ for both lead and cadmium ions. This is well within the limits of lead and cadmium ions in the real sample matrices whose compositions are given in Table 3.

\section{Conclusions}

A new binderless covalent bulk modified electrode has been proposed and successfully utilized in the simultaneous determination of $\mathrm{Pb}^{2+}$ and $\mathrm{Cd}^{2+}$ ions by differential pulse anodic stripping voltammetry. The methodology of the present approach is toward green and the modified electrode has the advantages of toxic free, ease of preparation in bulk quantities, long term storage and operational stability over a period of several months without leaching of the modifier into the bulk of the electrolytic solution when compared to other carbon paste and surface modified rigid electrodes. The electrode surface can be renewed by simple mechanical polishing using different grades of emery sheets as opposed to that of conventional electrochemical cleaning which require prolonged time. Therefore the developed sensor electrode offers an alternative route to monitor the heavy metal ion concentrations at trace level without any constraints as encountered in the conventional existing electrodes. Hence the proposed electrode has been used in the simultaneous determination of lead and cadmium ions from industrial effluents at trace level.

\section{Acknowledgement}

The authors acknowledge the financial support and award of Junior Research Fellowship (JRF) to GKR by the Department of Science \& Technology (DST), New Delhi, India.

\section{References}

[1] I. Cesarino, E.J. Cavaltheiro, C.M.A. Brett, Electroanalysis 22 (2010) 61.

[2] L.T. Viyannalage, S.B. Bliznakov, N. Dimitrov, Anal. Chem. 80 (2008) 2042.

[3] El Mhammedi, M. Achak, A. Chtaini, J. Hazard. Mater. 161 (2009) 55

[4] I.A. Darwish, D.A. Blake, Anal. Chem. 74 (2002) 52.

[5] M.G. Tan, G.L. Zhang, X.L. Li, Y.X. Zhang, W.S. Yue, J.M. Chen, Y.S. Wang, A.G. Li, M. Zhang, Z.C. Shan, Anal. Chem. 78 (2006) 8044.

[6] L. Xiao, G.G. Wildgoose, R.G. Compton, Anal. Chim. Acta 620 (2008) 44

[7] B.K. Jena, C.R. Raj, Anal. Chem. 80 (2008) 4836.

[8] K. Seo, S. Kim, J. Park, Anal. Chem. 70 (1998) 2936.

[9] H.P. Mwu, Anal. Chem. 66 (1994) 3151. 
[10] M. Lu, E. Kathryn, R.G. Compton, Electroanalysis 22 (2010) 1

[11] J. Wang, J. Lu, S. Hocevar, P.A.M. Farias, Anal. Chem. 72 (2000) 3218

[12] X.H. Yang, P. Zing, J. Jin, Litong, Chin. J. Chem. 28 (2010) 2287.

[13] D.W.M. Arrigan, Analyst 119 (1994) 1953.

[14] Y. Zhang, Y. Liu, X. Ji, C.E. Banks, W. Zhang, Chem. Commun. 47 (2011) 4126.

[15] T. Sheela, S. Basavanna, R. Viswanath, H.C.B. Kalachar, Y. Arthoba Naik, Electroanalysis 23 (2011) 1150 .

[16] J. Ping, J. Wu, Y. Ying, M. Wang, G. Liu, M. Zhang, J. Agric. Food Chem. 59 (2011) 4418.

[17] N. Motta, A.R. Guadalupe, Anal. Chem. 66 (1994) 566.

[18] Y. Li, X. Liu, X. Zeng, Y. Liu, X. Liu, W. Wei, S. Luo, Sens. Actuators B 139 (2009) 604.

[19] P. Ramesh, S. Sampath., Anal. Chem. 72 (2000) 3369.

[20] C.R.T. Tarley, M.A.Z. Arruda, Chemosphere 54 (2004) 987.

[21] G.K. Ramesha, S. Sampath, Electroanalysis 19 (2007) 2472

[22] N. Zhang, H. Qiu, Y. Si, W. Wang, J. Gao, Carbon 49 (2011) 827.

[23] L. Fan, J. Chen, S. Zhu, M. Wang, G. Xu, Electrochem. Commun. 11 (2009) 1823

[24] M. Pandurangappa, T. Ramakrishnappa, J. Solid State Electrochem. 14 (2010) 687.

[25] H.P. Boehm, Carbon 32 (1994) 759.
[26] Z. Wang, M.D. Shirley, S.T. Meikel, D. Whitby, Carbon 47 (2009) 73.

[27] M.N. Kirikova, A.S. Ivanov, S.V. Savilov, V.V. Lunin, Rus. Chem. Bull. 57 (2008) 298.

[28] S.T. Yang, Y. Chang, H. Wang, G. Liu, S. Chen, Y. Wang, Colloid J. Interface Sci. 351 (2010) 122.

[29] P. Ramesh, P. Shivakumar, S. Sampath, J. Electroanal. Chem. 528 (2002) 82

[30] P. Abiman, A. Crossley, G.G. Wildgoose, J.H. Jones, R.G. Compton, Langmuir 23 (2007) 7847.

[31] A.T. Masheter, L. Xiao, G.G. Wildgoose, A. Crooseley, J.H. Jones, R.G. Compton, J. Mater. Chem. 17 (2007) 3515.

[32] G. Li, J. Liu, T. Bocking, P.K. Eggers, J.J. Gooding, Chem. Phys. 319 (2005) 136

[33] T.H. Degefa, B.S. Chandravanshi, H. Alemu, Electroanalysis 11 (1999) 1305.

[34] Inczedy, Janos, Analytical Applications of Complex Equilibria, Ellis, Horwood, New York, 1976.

[35] C.G. Hu, K.B. Wu, X. Dai, S.S. Hu, Talanta 60 (2003) 17.

[36] K. Wu, S. Hu, J. Fei, W. Bai, Anal. Chim. Acta 489 (2003) 215.

[37] S. Yuan, W. Chen, S. Hu, Talanta 64 (2004) 922.

[38] D. Stankovic, D. Manojlovic, G. Roglic, S.K. Rajacic, I. Andjelkovic, B. Dojcinovic, J. Mutica, Electroanalysis 23 (2011) 1928. 